\title{
Effect of gamma radiation on creep behavior, hardness and microstructure of Titanium dental material
}

\author{
Abu Bakr El-Bediwi ${ }^{1 *}$, Eman Kashita ${ }^{2}$, Salah, M .M.Salman ${ }^{2,3}$ \\ ${ }^{1 *}$ Physics Department, Faculty of Science, Mansoura University, Egypt \\ ${ }^{2}$ Educational Services, Qassim University, Ministry of High Education, Kingdom of Saudi Arabia \\ ${ }^{3}$ Physics Department, Faculty of Science, Helwan University, Ain-Helwan \\ baker_elbediwi@yahoo.com
}

\section{ABSTRAT}

Effect of gamma radiation with fixed doses on creep behavior, Vickers hardness, maximum shear stress and surface roughness parameters of $\mathrm{cp}$ Titanium have been investigated. Vickers hardness and maximum shear stress values of $\mathrm{cp}$ Titanium are decreased after irradiated at 10, 20 and $30 \mathrm{kGy}$. Surface roughness $\mathrm{Ra}$ of $\mathrm{cp}$ Titanium varied after irradiated at 10, 20 and $30 \mathrm{kGy}$. Stress exponent values of $\mathrm{cp}$ Titanium decreased after irradiated at 10, 20 and $30 \mathrm{kGy}$. Matrix microstructure of $\mathrm{cp}$ Titanium changed (Intensity, broadness and position) after irradiated at 10, 20 and $30 \mathrm{kGy}$.

Key words: - gamma radiation, creep, hardness, cp Titanium, stress exponent

\section{INTRODUCTION}

Titanium and some of its alloys are used as biomaterials for dental and orthopedic applications. Titanium is used in condensers and turbine blades in electric power plants. Because of its corrosion resistance, titanium and its alloys are used extensively in prosthetic devices such as artificial heart pumps, pacemaker cases, heart-valve parts and load bearing bone or hip-joint replacements or bone splints. Since titanium does not become magnetized, it is used in the structural parts surrounding computer components such as disk drives and microchips, which can be ruined by stray magnetism. Effect of gamma radiation on electrochemical corrosion behavior, structural morphology and hardness of silver-palladium and $\mathrm{Ni}-\mathrm{Cr}$ based alloys have been investigated [1,2]. Also the effect of gamma radiation on morphology structural, hardness and bending strength of dental porcelain have been studied and analyzed [3, 4]. El-Bediwi et al [5] studied the influence of therapeutic dose gamma radiation and MRI on structure and mechanical properties of resin-composites dental materials. The mechanical behavior of Ti-6Al-4V has been studied over a large range of temperature, from very low temperature $[6,7]$ to very high temperature [8]. Tensile properties of Ti-6Al-4V have been characterized over a large range of temperature, from room temperature to $600^{\circ} \mathrm{C}$ [9]. The aim of our research was to study the effect of gamma radiation at fixed doses on creep behavior, hardness and microstructure of $\mathrm{cp}$ titanium dental material.

\section{Material and methods}

Specimens of $\mathrm{cp}$ Titanium plates [(10 mm x $10 \mathrm{~mm} \times 1 \mathrm{~mm}$ ) (ASTM, Grade IV, Modern Techniques and Materials Engineering Center, Egypt)] were machined, ground on a 600-grit silicon carbide paper (Leco Co., St. Joseph, MI, USA) under running water and then cleaned in an ultrasonic (Bandelin, Sonorex, Germany) bath filled with distilled water for 5 min. Microhardness test of used specimens were conducted using a digital Vickers microhardness tester, (Model FM-7, Tokyo, Japan), applying a load of $100 \mathrm{gf}$ for 5 seconds via a Vickers diamond pyramid. The roughness of used samples were measured by using surface roughness measurements device (S.J 201.P). For indentation creep, Vickers microhardness tester at different load and time was used. There exists a linear relationship between indentation time and hardness for all conditions. The slope of the resultant lines according Mulheam-Tabor method is $-\left(n+\frac{1}{2}\right)$ where $\mathrm{n}$ is the stress exponent [10].

\section{RESULTS AND DISCUSSION}

\subsection{Creep behavior}

Creep behavior of $\mathrm{cp}$ Titanium after irradiated at 10,20 and $30 \mathrm{kGy}$ was investigated by indentation method performed at room temperature. The indentation creep data where the indentation length is plotted versus the indentation time at 10 , 20 and $30 \mathrm{kGy}$ is shown in Figure 1a. The indentation length increased with the loading time and the applied load increased. The curves shown in Figure 1a consist of two stages similar to an ordinary creep curve. The first stage of the curve records an increase in the indentation length with loading time followed by a steady-state region where indentation sizes increase linearly with time. Fracture of the specimen dose not occurs and it is not possible to record a third stage of the curve as opposed to what happens in an ordinary creep test because the hardness test is a compression test.

In the Mulheam-Tabor method, Figure 1b, Vickers hardness number of cp Titanium after irradiated at 10, 20 and $30 \mathrm{kGy}$ is plotted versus indentation time on log-log scale for the indentation data. The stress exponent values of $\mathrm{cp}$ Titanium after irradiated at 10, 20 and $30 \mathrm{kGy}$ are given in Table 1. The range of exponent values from 19.9 to 12.9 depending on irradiated doses. The change in stress exponent values attributed to microstructural features, (changed in titanium matrix such as lattice parameters, solid solution, size and distribution of strengthening phases) and that is agree with pervious results [11-13]. Stress exponent values also dependent on grain boundary and grain size, which dislocation movement affecting [14]. 
Table 1:- Stress exponent of $\mathrm{cp}$ Titanium before and after irradiated

\begin{tabular}{|c|c|}
\hline Samples & Stress exponent \\
\hline Titanium & 19.91 \\
\hline 10 kGy & 17.68 \\
\hline 20 kGy & 15.21 \\
\hline 30 kGy & 12.89 \\
\hline
\end{tabular}
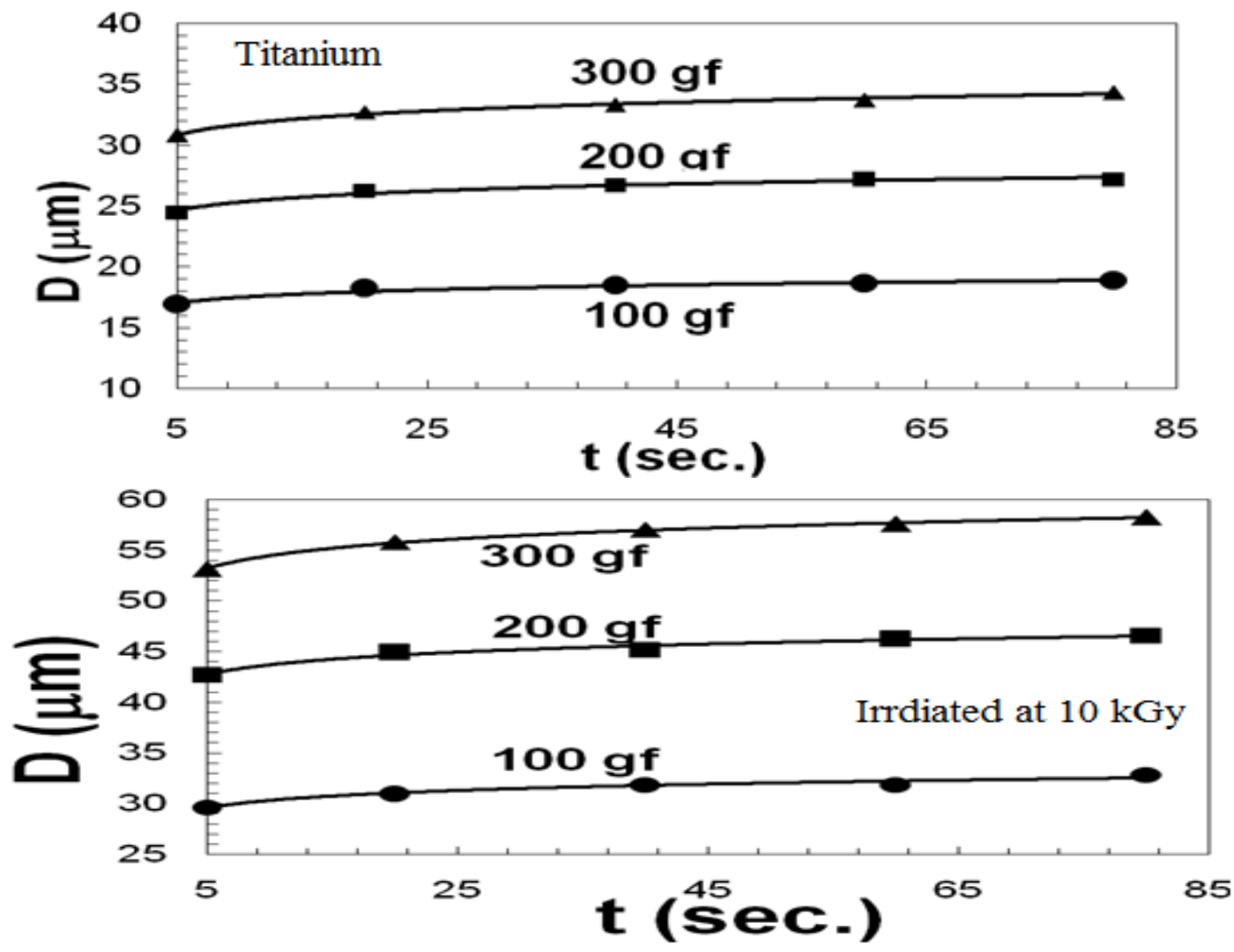

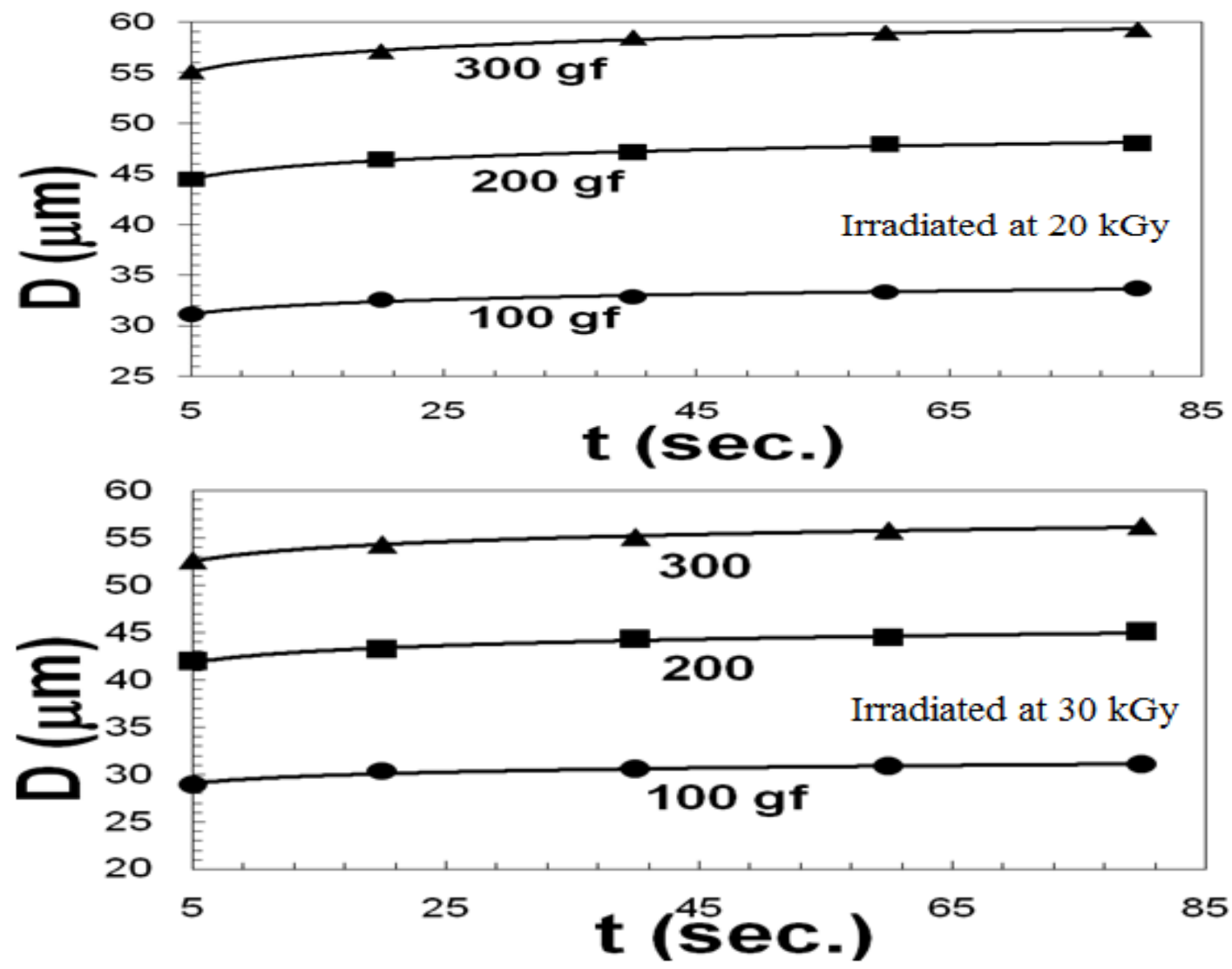

Fig. 1a:- the indentation length is plotted versus the indentation time
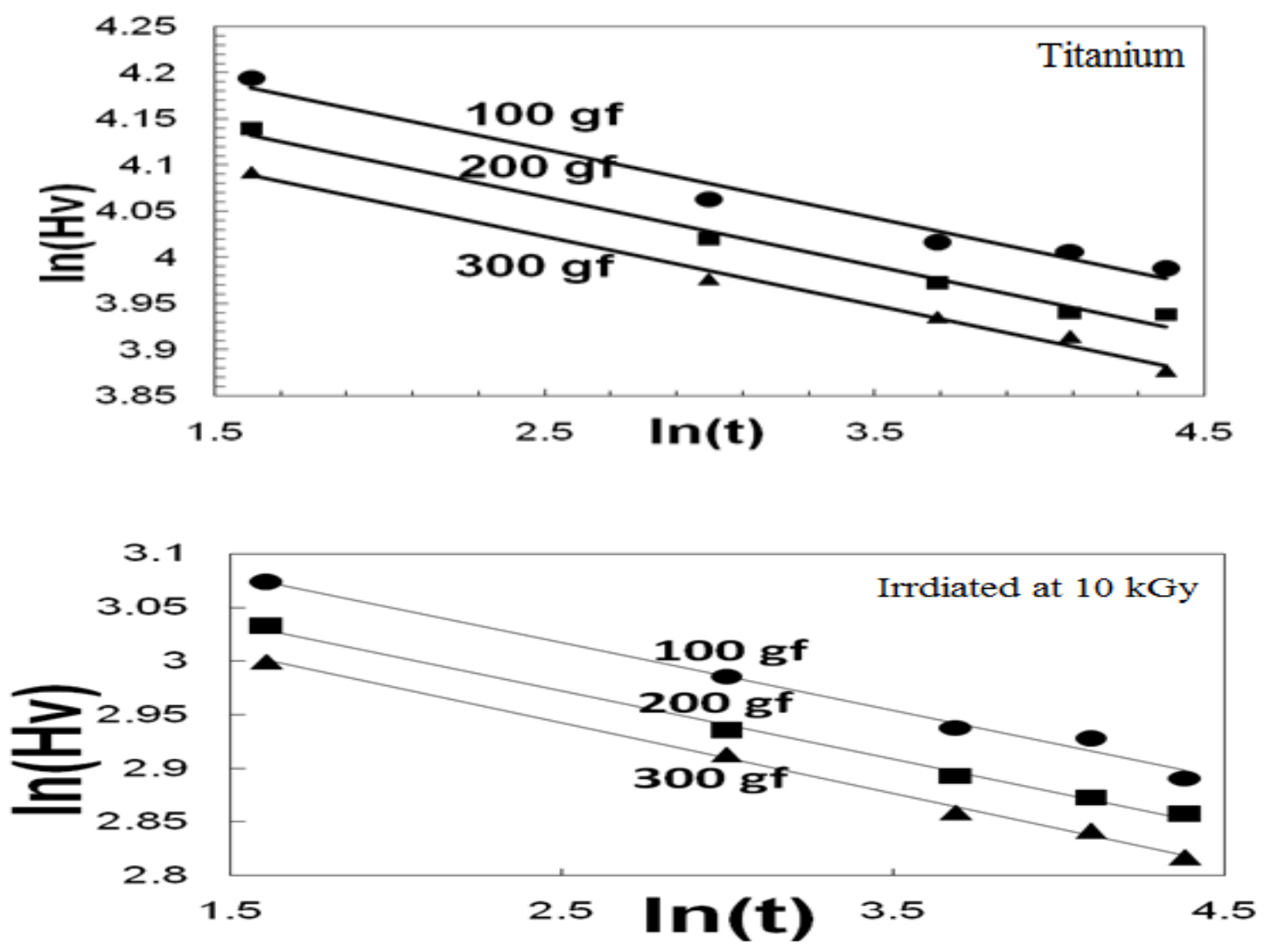

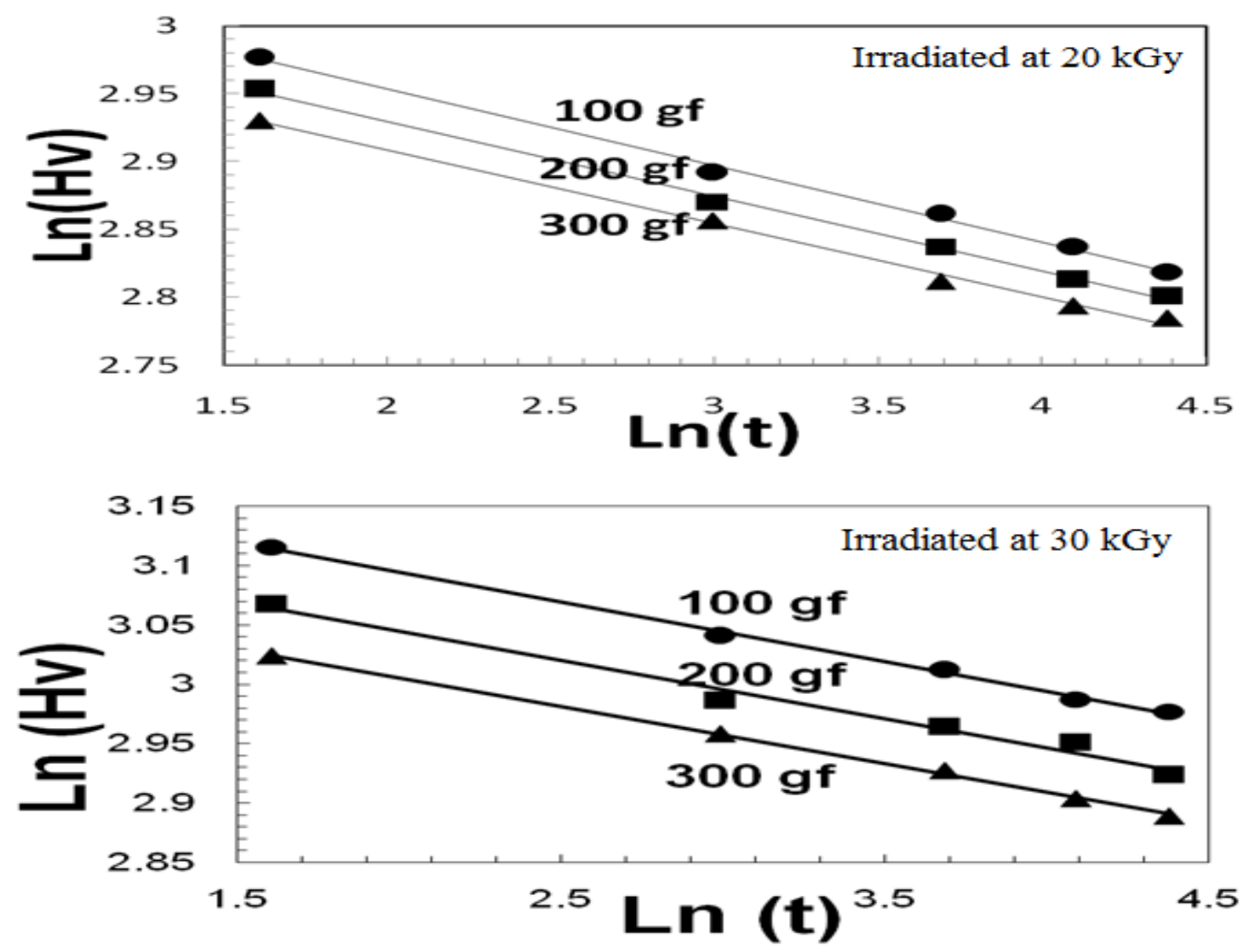

Fig. 1b:- Vickers hardness versus indentation time on log-log scale

\subsection{Surface properties}

\section{Vickers hardness}

Measured Vickers hardness and calculated maximum shear stress of $\mathrm{cp}$ Titanium decreased after irradiated at 10, 20 and $30 \mathrm{kGy}$ as seen in Table 2. That is because irradiated Titanium by gamma radiation doses changed its matrix microstructure such as crystal size with disturbed a solid solution and formed strengthens phases.

Table 2:- Vickers hardness and calculated maximum shear stress of $\mathrm{cp}$ Titanium before and after irradiated

\begin{tabular}{|c|c|c|}
\hline Alloys & $\mathrm{H}_{\mathrm{v}} \mathrm{kg} \backslash \mathrm{mm}^{2}$ & $\mu_{\mathrm{m}} \mathrm{kg} \backslash \mathrm{mm}^{2}$ \\
\hline Titanium & $654.1 \pm 16.89$ & 215.85 \\
\hline 10 kGy & $212 \pm 29.64$ & 69.96 \\
\hline 20 kGy & $192.5 \pm 31.06$ & 63.53 \\
\hline 30 kGy & $222.1 \pm 28.91$ & 73.29 \\
\hline
\end{tabular}

\section{Roughness}

The roughness profiles of $\mathrm{cp}$ Titanium before and after irradiated at 10, 20 and $30 \mathrm{kGy}$ are shown in Figure 2 . The average surface roughness parameter $\mathrm{Ra}$ along the total sliding distance increased after irradiated at 10, 20 and $30 \mathrm{kGy}$ as shown in Table 3. Also other roughness parameters changed after irradiated.

Table 3:- roughness parameters of cp Titanium before and after irradiated

\begin{tabular}{|c|c|c|c|c|}
\hline \multirow{2}{*}{$\begin{array}{c}\text { Roughness } \\
\text { parameters }\end{array}$} & base & 10 kGy & 20 kGy & 30 kGy \\
\cline { 2 - 5 } & 0.18 & 0.32 & 0.40 & 0.29 \\
\hline Ra um & 1.13 & 2.79 & 1.80 & 1.60 \\
\hline Rz um & &
\end{tabular}




\begin{tabular}{|l|l|l|l|l|}
\hline Rq um & 0.22 & 0.47 & 0.51 & 0.35 \\
\hline Rt um & 2.04 & 8.15 & 3.30 & 2.02 \\
\hline Rp um & 0.57 & 1.54 & 0.93 & 0.75 \\
\hline
\end{tabular}
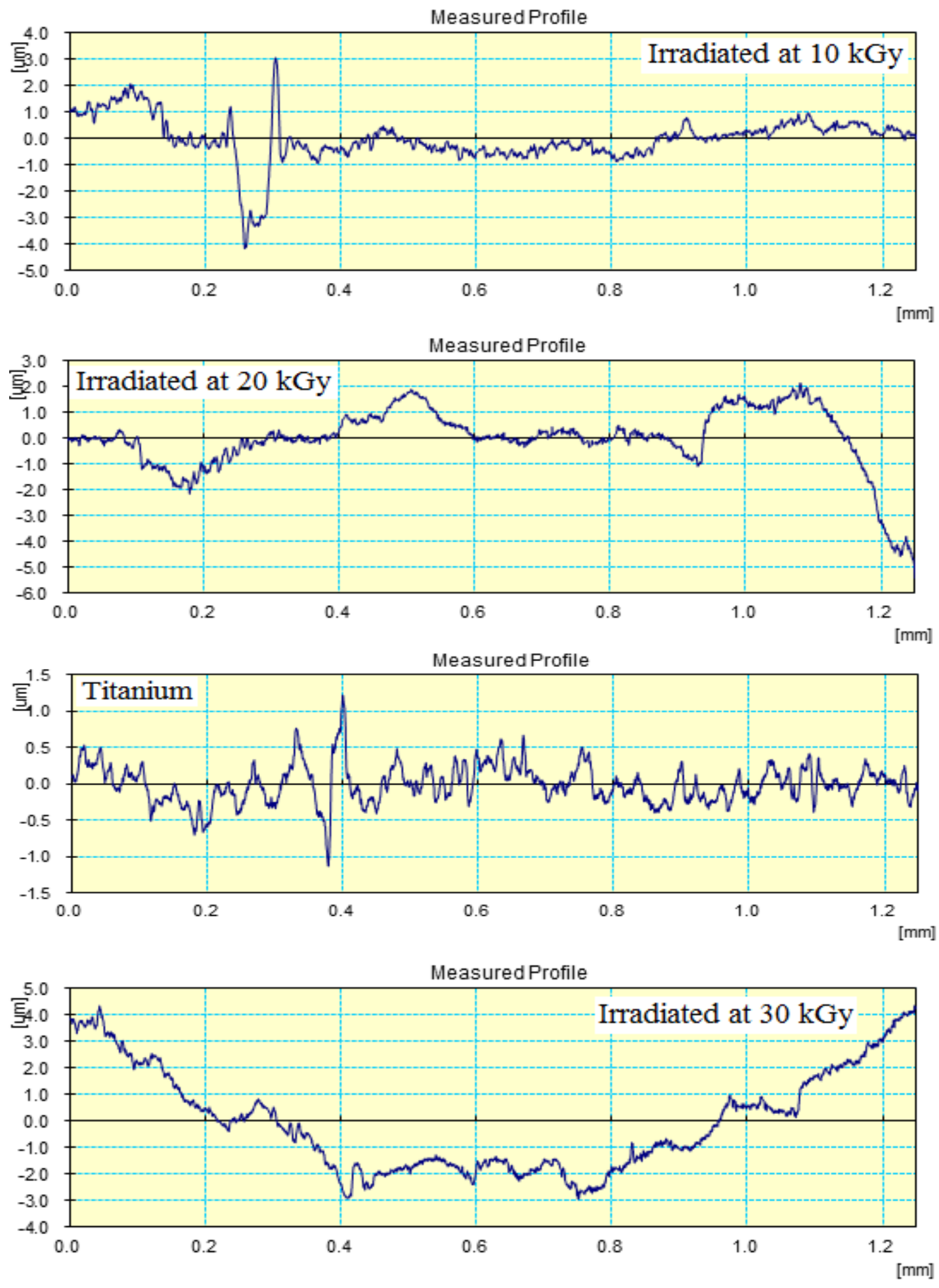

Fig. 2:- roughness profiles of $c p$ Titanium before and after irradiate 


\subsection{Microstructure}

Microstructure of $\mathrm{cp}$ Titanium before and after irradiated at 10, 20 and $30 \mathrm{kGy}$ are studied by x-ray diffractometer and shown in Figure 3. The X-ray diffraction patterns show sharp lines of hexagonal Ti phase is found in untreated Titanium, also the feature of Titanium phase (intensity, broadness and position) changed after exposure to gamma radiation.
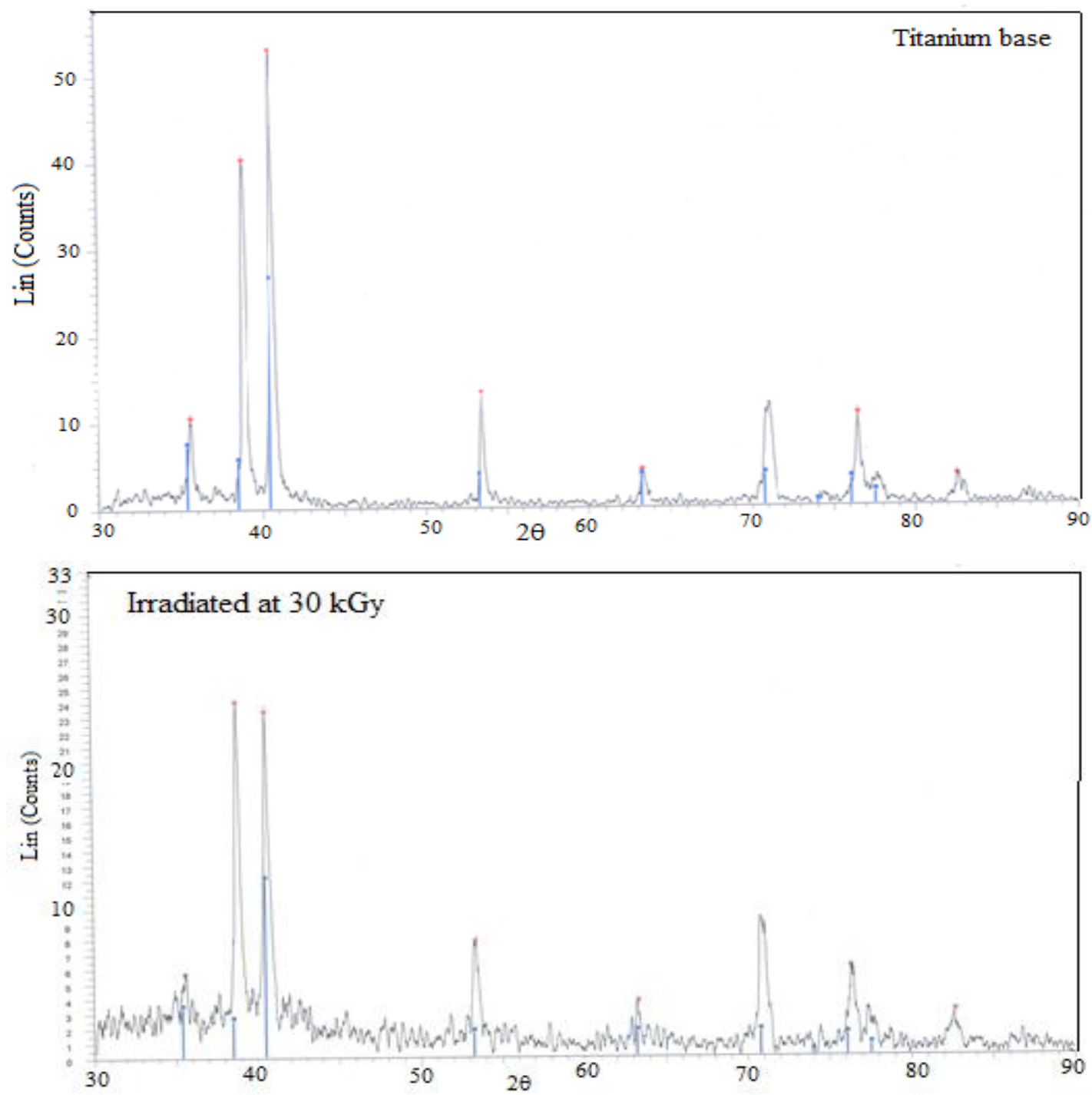

Fig. 3:- X-ray diffraction patterns of Titanium before and after irradiated

\section{CONCLUSION}

1. Vickers hardness and maximum shear stress values of $\mathrm{cp}$ Titanium decreased after irradiated at 10,20 and 30 kGy.

2. Surface roughness parameter, $\mathrm{Ra}$, of $\mathrm{cp}$ Titanium varied after irradiated at 10, 20 and $30 \mathrm{kGy}$.

3. Stress exponent values of $\mathrm{cp}$ Titanium decreased after irradiated at 10, 20 and $30 \mathrm{kGy}$.

4. Matrix microstructure of $\mathrm{cp}$ Titanium changed (crystallinity, crystal size and orientation) after irradiated at 10, 20 and $30 \mathrm{kGy}$.

\section{REFERENCES}

El-Bediwi A.B, Radwan N.K, Abdeen S, Al- Ragaei D, MSAIJ, 12: 6 (2015) 213

1. El-Bediwi A.B, Saad M, El-Fallel A, Radia. Eff. Def. Sol. 164: 11 (2009) 712

2. El-Bediwi A.B, A. Sakrana A, Research \& Rivews in BioScience, 7: 2 (2013) 72

3. El-Bediwi A.B, T. El-Helaly, A. Sakrana, M. Kamal, MSAIJ, 8: 12 (2012) 488

4. El-Bediwi A, El-Fallel A, El-Naga O.A, MSAIJ, 6: 2 (2010) 1 
5. Luo J, Li M, Yu W and Li H, Mater. Design, 31: 2 (2010) 741

6. Odegard B.C and Thompson A.W, Metallurgical Transactions A, 5 (1974) 1207

7. Niu Y, Li M, Hou H, Wang Y and Lin Y, ASM International, Vol. JMEPEG, 19 (2010) 59

8. Surand M, Viguier B, Herny E and Ruau J, MS\&T (2012), Vol. 2, Pittsburgh, (2012) 1518

9. Mulhearn TO, Tabor D. J Inst Metals, 89 (1960) 7

10. Mulhearn TO, Tabor D. J Inst Metals, 89 (1960) 7

11. El-Bediwi A, Bader S, Farag Z, Global Journal of Physics, 4: 2 (2016) 422

12. El-Bediwi A, Ismail K, Kamal M, MSAIJ, 9: 2 (2013) 73

13. El-Bediwi A, Saad M, El-Fallel A, El-Helaly T, J. Biophys. Biomed. Sci. 2: 1 (2009) 121

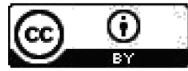

This work is licensed under a Creative Commons Attribution 4.0 International License.

DOI : 10.24297/jap.v13i8.6319 